\title{
STAND UP COMICS: INSTRUCTIONAL HUMOR AND STUDENT ENGAGMENT
}

Amy Wortley, Grand Canyon University

Elizabeth Dotson, Eastern Washington University

\begin{abstract}
This paper examines the use of instructional humor in higher education settings and makes connections between the levels of student achievement in academics and the influence of appropriate instructional humor. The work of prominent researchers such as Wanzer, Frymier, and Irwin (2010), and Segrist \& Hupp (2015), who postulate that instructional humor and student information processing are intimately connected, drives much of the research foundation. Humor not only encourages student retention of information but serves to create a hospitable, welcoming atmosphere which makes learning more enjoyable for all involved. This closely corresponds with the work of Merolla (2006) and his research on decoding ability and humor production, and is expanded upon in terms of student psychological wellness (Conley, Travers, and Bryant, 2013). The connections between information retention and stress are shown to be alleviated in part by appropriate instructor humor usage.
\end{abstract}

Keywords: Instructional Humor, College Students, Humor Orientation, YouTube in Education, Social Media, Memory and Stress

Maybe you have heard this one before: "a priest, a nun, and a rabbi walk into a bar..." Humor is subjective. What has one person rolling on the floor can be shrugged off by another with an expansive eye-roll and a huff of exasperation. Just as successful comedians must connect with and engage an audience, a successful instructor must strive to engage his/her audience: the students. Many education programs now tell potential educators that teaching is a performance art, and scholars such as Wanzer, Frymier, and Irwin (2010) contended appropriate instructional humor usage in the classroom not only engages an audience, but is directly connected to student learning and achievement.

"Generally speaking, humor can positively impact people's lives [...] studies have linked humor to low stress levels, high self-esteem, empathy, and interpersonal attractiveness" (Merolla, 2006). It is commonly held that a student's time in college will be intrinsically stressful, and when a student experiences stress, they often fail to achieve academically. College students report high levels of stress in the first year away from home, citing loneliness, homesickness, conflict, and distress in interpersonal relationships as the primary causes (Conley, Travers, \& Bryant, 2013). However, because such a cultural stigma about seeking professional assistance remains firmly entrenched, "only about $10 \%$ of students on a traditional campus will seek and receive mental health services" (2013). In such an environment, a student's instructors can make a meaningful difference in mental wellness, in addition to supporting their academic achievement, by incorporating appropriate humor into their teaching pedagogy. The focus of this paper is to show the positive correlation between appropriate instructional humor and student success.

APPROPRIATE INSTRUCTIONAL HUMOR

The Instruction Humor Processing Theory 
(IHPT) incorporates elements of IncongruityResolution Theory, Disposition Theory, and the Elaborations Likelihood Model (ELM) of persuasion (Wanzer, Frymier \& Irwin, 2010). The IHPT contends that appropriate forms of instructional humor are positively associated with student learning. Martin, Phulik-Doris,Larsen, Grey, and Weir (2003) defined varieties of instructional humor as they noted "humor is used as a means of relating to others in prosocial and positive ways, it is adaptive" (p. 50). Adopting appropriate varieties of instructional humor allows for instructors to utilize their own conceptual framework to assess their students' interests and areas of concern; thereby, creating a uniquely personalized classroom experience and community. Personalized instruction incorporating humor encourages student engagement and results in increased information retention. Merolla (2006) explained this connection as "arousal framed explanations" to elucidate on the relationship between humor and recall.

Humor has been described as an attention gaining strategy in the educational setting, and often serves as a means of generating positive response and retention. Torok, McMorris, and Lin (2004) found $74 \%$ of college students surveyed indicated they appreciated the use of humor by their instructors (p. 16). Additionally, $40 \%$ of those surveyed acknowledged humor "often" facilitated their learning in the classroom, and $40 \%$ of students responded that humor "always" helped them be successful in their learning (Torok, et. al., 2004, p. 16). These numbers should not come as much of a surprise to educators who have tried to connect with apathetic students sitting glassyeyed in their seats. This concept also is supported by Robert Gagné's first "event" in his Nine Events of Instruction: Gain Attention (2015). "These were based on the information processing model of the mental events that occur when adults are presented with various stimuli" (Gagné, 2015). However, the caveat is that to be most effective in helping students create associations, any attention getter needs to be relevant to the instruction that follows.

Students seem to crave entertainment, not just in their technology, pop-culture, and social media, but in their education as well. The days of the Ivory Tower as the source of knowledge, generously meted out to motivated learners in ninety minute lectures, may have bid a fond farewell to its era of effectiveness. Research has now found instructors' usage of closely related content based humor is positively correlated with student learning. This type of humor should enhance student motivation and information processing in its approach (Wanzer, Frymier \& Irwin, 2010). Segrist \& Hupp (2015) put forward the idea "instructor's use of humor was positively associated with students' perceptions that the instructor has a 'positive attitude' toward them, 'wanted them to succeed', and displayed a 'genuine concern for them" (p. 14). However, not every instructor is a born comedian, deftly wielding their humor to cut down student apathy. The lack of natural comedic tendencies does not mean every instructor cannot incorporate a more personal brand of comedy in their courses. "A trait based perspective of humor holds that individuals who are high in humor orientation see more situations as appropriate for their humor attempts" (Merolla, 2006, p. 176). Some instructors are naturally gifted in a witty turn of phrase or a well-timed quip. The incorporation of humor flows naturally, and students engage with the material their instructors present with an equally natural inclination. The instructors' skill in humor delivery can be a meaningful factor in students' responses to the utilized comedy. But, like any other skill, instructional delivery of humorous content can be improved through practice, planning and the incorporation of humor in a variety of presentation formats (i.e., videos, comic strips, PowerPoints).

\section{PRACTICAL APPROACHES TO HUMOR APPLICATION}

Dewitt and Vergut's (2001) selectionist theory of humor production entailed sensitivity to social environments as critical in the enactment of humor (p. 39). Educators are known to be, as a whole, socially conscious and naturally reflective as a species, so the idea of displaying a sensitivity to social environments is a familiar one (Conley, Travers, and Bryant, 2013). Wanzer, Frymeir, and Irwin (2010) acknowledged the first step in understanding how humor is processed within the context of education involves heightened awareness of the humorous stimuli in the classroom setting. Humor attempts are labeled "highly appropriate" when they relate closely to the course content (2010). A course can be designed to incorporate content-appropriate comedy through the use of visual systems of information delivery such as 
videos and comic strips. This is a good technique for an instructor who does not yet feel comfortable playing the comedian themselves.

Video incorporation from sources as seemingly banal as YouTube can spike student interest and reengage memory retention. In fact, research suggests that content and humor targeted YouTube videos enhance student engagement, depth of understanding, and overall satisfaction in higher education courses (Buzzetto-More, 2014). In this same study, "70.7\% of participants surveyed "agreed/strongly agreed" the use of YouTube as a learning tool engages students" (p. 25). The incorporation of instructional humor through a visual medium can prove highly effective for educators who wish to integrate comedy in the classroom to promote learning.

\section{INAPPROPRIATE INSTRUCTOR HUMOR}

While the use of appropriate instructor-based humor can be an effective method for increasing student engagement and information recall, inappropriate humor can have an equally powerful effect. Not all modes of humor are appropriate in the classroom. Aggressive, student-targeted, and other maladaptive forms of instructor humor were correlated positively with neuroticism and the use of a self-defeating style of humor delivery correlated with depression, anxiety, and hostility (Wanzer, Frymier \& Irwin, 2010). This negative association between inappropriate humor and psychological well-being should be used as a caution against some specific comedic types. Humor at other's expense, humor that "goes over students' heads," or humor that confuses a student all have a negative impact on the academic experience. Disposition Theory (Zillman \& Cantor, 1996) explains when a student feels they, or one of their classmates, is the "butt" of a joke, the individuals label the instructor's humor usages as "inappropriate". This label then generates a negative effect in the learning environment (1996). While humor is often described in education circles as an attention getting strategy, when the humor falls into one of the negative usage categories it serves as a distraction from the instructional message. This distraction often results in a reduced ability to process the delivered information (Wanzer, Frymier \& Irwin, 2010).

Some humor forms walk a thin line between appropriate and inappropriate. Self-deprecating humor is one of these tight rope walking modes.
"Instructor use of self-disparaging humor could reduce status differentials and increase perceptions of closeness" (Wanzer, Frymier \& Irwin, 2010, p. 8). By breaking down real and perceived barriers between students and instructors, open and honest conversations and effective academic discourse can take place, resulting in higher levels of student engagement and achievement. Conversely, an instructor's use of this self-deprecating comedic mode may reduce their credibility in the eyes of their pupils and thereby violate the student's expectations related to the instructor's knowledge and competence. This negative perception of the instructor may result in "a negative affective response, and decreased student motivation" (Wanzer, Frymier \& Irwin, 2010, p. 8). Therefore, some level of caution should be implemented when utilizing humorous content in the classroom, emphasizing the difference between appropriate and inappropriate comedic modes.

\section{PHYSIOLOGICAL AND PSYCHOLOGICAL CONNECTIONS BETWEEN HUMOR AND WELLNESS}

The use of instructor humor engages apathetic students on an educational level, but the physiological impacts of humor can be equally significant in terms of student wellness. Many college-level students experience varying levels of stress during their academic careers. Generally defined, stress is the experience of anticipating or encountering adversity in one's goal-related efforts (Carver \& Conner-Smith, 2010). Stress has been linked to absenteeism, loss of productivity, and interpersonal relationship related strife (Anchor, Crum \& Salovey, 2013). "Physiologically, the 'stress response' is the activation of the sympathetic nervous system, a parasympathetic withdrawal, and increased activity of the hypothalamic-pituitary-adrenal axis," (KunzEbrecht, Mohamed-Ali, Feldman, Kirschbaum, \& Steptoe, 2003, p. 373). Laughter, initiated through instructional humor, decreases stress hormones and acts to mitigate the effects of stress on the cardiovascular system (Chang, Tsai \& Hsieh, 2013). Students who score high on sense of humor are found to experience fewer negative stressful life events (Lefcourt \& Martin, 1986). For these students, humor is associated with a positive self-concept as well as a greater acceptance of life circumstances. Current research suggests humor may contribute to the reappraisal of stressful life events from being 
"threatening" to being interpreted as a "challenge" (Nezu, Nezu, \& Blissett, 1988). This reappraisal helps students to gain a sense of control over the stressor and can lead to increased classroom success (Capps, 2006). Studies have demonstrated the use of humor by undergraduate students is an effective coping mechanism for school-related stressors.

\section{HUMOR, ENHANCED MEMORY AND INFORMATION RETENTION}

In addition to being an effective coping mechanism in the reduction of student stress, humor can also serve as a means of enhancing student memory and information retention. Humor has been found to affect memory in both intentional and incidental humorous memory situations (Carlson, 2011), meaning students' retention of material is positively affected by classroom humor whether or not it was intentional on the part of the instructor. The perception of humor remains an important component in the humor-memory relationship. The retrieval processes of memory encoding are positively influenced by humor, this effect can be observed in the Incongruity Resolution Hypothesis posited by Carlson. The resolution of semantic incongruities associated with humor creates a memory advantage for the humorous material, resulting in advantaged recall and enduring memory for the material (Carlson, 2011). In the study, Carlson (2011) found it was not necessary for students to intentionally process humor in order for the humor effect to emerge. This may be encouraging to instructors in that students may not necessarily need to fully comprehend the humorous aspect of material for its benefits to be experienced. While humor is known to affect memory, there are inconsistent findings as to the mechanisms through which this relationship consists. Current research suggests humor may work indirectly on memory through other mechanisms, such as rehearsal, surprise, arousal, incongruity or constraints on the reconstructive process (Summerfelt, 2010). The emotional aspects of humor may also aid in its relationship with memory and recall. Humor creates effective levels of arousal, which, in turn, create a more salient and accessible form of memory retention and retrieval (Derks, Gardner, \& Agarwal; 1998, Summerfelt, 2010). This retrieval is aided through classroom humor insomuch as a student's attempt to understand a joke leads to increased arousal, which in turn leads to increased retrieval and recall. This process contributes to the saliency of material presented and constitutes a stronger connection between the material and student recollection, thereby enhancing engagement.

\section{HUMOR, MEMORY, AND STRESS}

Now that we have examined the relationships between humor and stress as well as humor and memory, we can better understand the interaction between the three components: humor, memory and stress. In a study conducted by Rickenbach, Almeida, Seeman \& Lachman (2014), the findings showed participants reported higher numbers of memory problems on stressor days, with a reported decline in working memory as well as general cognitive decline. When an individual experiences a stressful event, the hypothalamic-pituitary-adrenal (HPA) axis in the brain triggers the release of the hormone cortisol, which helps the individual react to a potentially dangerous or threatening event (Rickenbach, et. al., 2014). While this response can be beneficial and productive in short-term stressful situations, escaping from a rabid mountain lion for instance; long-term, chronic stress, much like that often experienced by students, can result in a dysregulated HPA response which contributes to an exacerbation of memory problems in both the encoding and recollection phases of memory. The dysregulated HPA response's effect on memory results from the negative effects of stress on the hippocampal region of the brain, which is responsible for memory functioning (McEwen \& Seeman, 1999). Rickenbach et. al's. research regarding stress and memory was founded in the Lifespan Developmental Theory which posits, "Longitudinal changes in objective cognition may be associated with increased vulnerability to the experience of daily stressors because of limited resources, reduced reserve capacity and constraints in dealing with activities and hassles of daily life," (Staudinger, Marsiske, \& Baltes, 1993). These findings suggest that students will have more difficulty recalling course material on days of high stress. This stress can be, at least in part, mitigated by the use of instructor humor and humorous lecture material as we have seen in the discussion of the previous paragraph. Humor aids in memory encoding as well as retrieval and also contributes to lower levels of both perceived and experienced stress. 


\section{CONCLUSION}

In conclusion, instructional humor, when used appropriately, can improve a student's academic experience and promote physiological and psychological wellness. Instructors can engage their students through many methods of integration: instructor delivery of humor, incorporation of visual humor through YouTube videos, and appropriate humor usage; thereby enabling students to absorb and retain more content focused information.

\section{References}

Abel,M.H. (2002). Humor, stress, and coping strategies. Humor: International Journal of Humor Research, 15(4), 365-381. doi: 10.1515/humr.15.4.365

Besser, A., \& Zeigler-Hill, V. (2011). Pathological forms of narcissism and perceived stress during the transition to the university: The mediating role of humor styles. International Journal of Stress Management, 18(3), 197-221. doi: 10.1037I a0024826

Buzzetto-More, N. A. (2014). An examination of undergraduate student's perceptions and predilections of the use of YouTube in the teaching and learning process. Interdisciplinary Journal of E-Learning and Learning Objects, 10, 17-32.

Capps, D. (2006). The Psychological Benefits of Humor. Pastoral Psychology, 54(5), 393-411. doi: 10.1007/s11089-005-0007-9

Carlson, K.A. (2011). The impact of humor on memory: Is the humor effect about humor? Humor: International Journal of Humor Research, 24(1), 21-41. doi: 10.1515/HUMR.2011.002

Carver, C. S., \& Connor-Smith, J. (2010). Personality and coping. Annual Review of Psychology, 61, 679-704.

Chang, C., Tsia, G., \& Hsieh, C. (2013). Psychological, immunological, and physiological effects of a laughing qigong program (LQP) on adolescents. Complementary Therapies in Medicine, 21. 660-668.

Conley, C. S., Travers, L. V., Bryant, F. B. (2013). Promoting psychosocial adjustment and stress management in firstyear college students: the benefits of engagement in a psychosocial wellness seminar. Journal of American College Health, 61. 75-86.
Dewitte, S., \& Verguts, T. (2001). Being funny: A selectionist account of humor production. Humor: International Journal of Humor Research, 14, 167-202.

Fouladi, R.T., Rew, L., \& Horner, S.D. (2006). Comparison of three modes of measuring stress, coping, and humor in school-age children. Journal of Nursing Measurement, 14(2), 79-98. doi: 10.1891/jnm-v14i2a002

Gagné, R. (2015, August 25). Gagné's 9 Events of Instruction. In Center for Instructional Technology \& Training. Retrieved November, 10, 2015.

Hupbach, A., \& Dorskind, J.m. (2014). Stress selectively affects the reactivated components of a declarative memory. Behavioral Neuroscience, 128(5), 614-620. doi: 10.1037/ bne0000006

Kunz-Ebrecht, S. R., Mohamed-Ali, V., Feldman, P. J., Kirschbaum, C., \& Steptoe, A. (2003). Cortisol responses to mild psychological stress are inversely associated with proinflammatory cytokines. Brain, Behavior, and Immunity, 17, 373-383.

Martin, R. A., Puhlik-Doris, P., Laresn, G., Gray, J., \& Weir, K. (2003). Individual differences in uses of humor and their relation to psychological well-being: Development of the humor styles questionnaire. Journal of Research in Personality, 37. 48-75.

Merolla, A. J. (2006). Decoding ability and humor production. Communication Quarterly, 54, 175-189.

Moran, C.C., \& Hughes, L.P. (2006). Coping with Stress: Social Work Students and Humor. Social Work Education, 25(5), 501-517. doi:10.1080/02615470600738890

Rickenbach, E.H., Almeida, D.M., Seeman, T.E., \& Lachman, M.E. (2014). Daily stress magnifies the association between cognitive decline and everyday memory problems: An integration of longitudinal and diary methods. Psychology And Aging, 29(4), 852-862. doi:10.1037/a0038072

Segrist, D.J. \& Jupp, S.D. (2015). This class is a joke! Humor as a pedagogical tool in the teaching of psychology. Psychology Teacher Network: American Psychological Association, 25(3), 14-15.

Summerfelt, H., Lippman, L., \& Hyman, I.J. (2010). The effect of humor on memory: Constrained by the pun. Journal Of General Psychology, 137(4), 376-394. doi: 10.1080/00221309.2010.49939

Torok, S. E., McMorris, R. F., \& Lin, W. (2004). Is humor an appropriate teaching tool? Perceptions of professors' teaching styles and use of humor. College Teaching, 52, 14-20. 
Wanzer, M. B., Frymier, A. B., \& Irwin, J. (2010). An explanation of the relationship between instructor humor and student learning: instructional humor processing theory. Communication Education, 59, 1-18.

Wu, J., \& Chan, R. C. (2013). Chinese teachers' use of humour in coping with stress. International Journal of Psychology, 48(6), 1050-1056. doi:10.1080/00207594.2012.734623

Zillman, D., \& Cantor, J. R. (1996). A disposition theory of humor and mirth. In A. J. Chapman \& H. C. Foot (Eds.), Humor and laughter: Theory, research, and applications (pp. 93-115). New Brunswick, NJ: Transaction Publishers.

\section{Author Biographies}

Amy Wortley is a professor, researcher, and writer in the College of Humanities and Social Sciences at Grand Canyon University. Her scholarship focuses on the usage of humor in education as a method for increased student engagement and information retention both online and in the traditional classroom setting. She has presented her work in these areas at professional conferences and as a contributor to an academic, peer-reviewed journal.

Elizabeth Dotson is a researcher for Washington State University and instructor at Eastern Washington University. Her scholarship focuses on neuropsychology and the long-term psychological effects of childhood maltreatment. She has presented her work in these areas at professional conferences and as a contributor to an academic, peer-reviewed journal. 